\title{
Nebulization with Gamma-Tocopherol Ameliorates Acute Lung Injury after Burn and Smoke Inhalation in the Ovine Model
}

\author{
Yusuke Yamamoto ${ }^{1,3}$, Perenlei Enkhbaatar ${ }^{1}$, Linda E. Sousse ${ }^{1}$, Hiroyuki Sakurai ${ }^{3}$, \\ Sebastian W. Rehberg ${ }^{1}$, Sven Asmussen ${ }^{1}$, Edward R. Kraft ${ }^{1}$, Charlotte L. Wright ${ }^{4}$, Eva \\ Bartha ${ }^{1}$, Robert A. Cox ${ }^{2}$, Hal K. Hawkins ${ }^{2}$, Lillian D. Traber ${ }^{1}$, Maret G. Traber ${ }^{4}$, Csaba \\ Szabo ${ }^{1}$, David N. Herndon ${ }^{5}$, and Daniel L. Traber ${ }^{1}$ \\ ${ }^{1}$ Department of Anesthesiology, University of Texas Medical Branch, Galveston, Texas \\ 77555-0833, USA \\ 2Department of Pathology, University of Texas Medical Branch, Galveston, Texas 77555-0833, \\ USA
}

${ }^{3}$ Department of Plastic and Reconstructive Surgery, Tokyo Women's Medical University, 8-1 Kawata-cho, Shinjuku-ku, Tokyo 162-8666, Japan

${ }^{4}$ Linus Pauling Institute, Oregon State University, Corvallis, Oregon 97331-6512, USA

${ }^{5}$ Shriners Hospitals for Children, Burn Unit, Galveston, Texas 77555-0833

\section{Abstract}

We hypothesize that the nebulization of gamma-tocopherol (g-T) in the airway of our ovine model of acute respiratory distress syndrome (ARDS) will effectively improve pulmonary function following burn and smoke inhalation after 96 hours. Adult ewes $(n=14)$ were subjected to $40 \%$ total body surface area burn and were insufflated with 48 breaths of cotton smoke under deep anesthesia, in a double-blind comparative study. A customized aerosolization device continuously delivered g- $\mathrm{T}$ in ethanol with each breath from 3 to 48 hours after the injury ( $\mathrm{g}$ - $\mathrm{T}$ group, $\mathrm{n}=6$ ), while the control group $(n=5)$ was nebulized with only ethanol. Animals were weaned from the ventilator when possible. All animals were sacrificed after 96 hours, with the exception of one untreated animal that was euthanized after 64 hours. Lung g-T concentration significantly increased after $\mathrm{g}$-T nebulization compared to the control group $(38.5 \pm 16.8 \mathrm{nmol} / \mathrm{g}$ vs. $0.39 \pm 0.46$, $p<0.01)$. The $\mathrm{PaO}_{2} / \mathrm{FiO}_{2}$ ratio was significantly higher after treatment with $\mathrm{g}$-T compared to the control group ( $310 \pm 152$ vs $150 \pm 27.0, p<0.05)$. The following clinical parameters were improved with g-T treatment: pulmonary shunt fraction, peak and pause pressures, lung bloodless wet-to-dry weight ratios $(2.9 \pm 0.87$ vs $4.6 \pm 1.4, p<0.05)$, and bronchiolar obstruction $(2.0 \pm 1.1 \%$ vs $4.6 \pm 1.7 \%$, $p<0.05)$. Nebulization of $\mathrm{g}-\mathrm{T}$, carried by ethanol, improved pulmonary oxygenation and markedly reduced the time necessary for assisted ventilation in burn and smoke injured sheep. Delivery of $\mathrm{g}$ $\mathrm{T}$ into the lungs may be a safe, novel, and efficient approach for management of ALI patients who have sustained oxidative damage to the airway.

\section{Keywords}

obstruction; alpha-tocopherol; pulmonary function; early excision

Please address reprint requests and correspondence to: Daniel L. Traber, Ph.D., University of Texas Medical Branch, 301 University Boulevard, Route 1102, Galveston, TX 77555-0833, Phone: (409) 772-6405, Fax: (409) 772-6409, dltraber@utmb.edu.

DISCLOSURES: None 


\section{INTRODUCTION}

Approximately 23,000 of the 1.25 million victims of thermal injury in the United States suffer concomitant injury from the inhalation of smoke (29). Smoke inhalation injury continues to complicate burn management. Inhalation injury alone increased mortality by a maximum of $20 \%$, and approximately $30 \%$ of burn patient with inhalation injury die $(16,30$, 39). The trauma caused by combined burn and smoke inhalation injury commonly results in a rapid pathophysiological response by the lung, an exaggerated inflammatory cascade, and acute lung injury (ALI) (43). Mortality in combined smoke inhalation injury and burn remains high despite effective fluid resuscitation, respiratory management, and early wound excision. Decreased antioxidant activity and increased lipid peroxidation in the lung, after smoke inhalation, may reflect the degree of injury and mortality $(9,25)$.

Combined burn and smoke inhalation injury is typically associated with increased concentrations of reactive oxygen species (ROS) and reactive nitrogen species (RNS) in the lung $(24,43)$. Reactive species can react with proteins, DNA, carbohydrates, and lipids in a destructive manner that results in oxidative stress (20). ROS include free radicals such as superoxide $\left(\mathrm{O}_{2}^{-}\right)$and hydroxyl $\left(\mathrm{OH}^{*}\right)$ radicals, and the non-radical molecule hydrogen peroxide $\left(\mathrm{H}_{2} \mathrm{O}_{2}\right)$. RNS include peroxynitrite $\left(\mathrm{ONOO}^{-}\right)$, nitrogen dioxide $\left(\mathrm{NO}_{2}\right)$, and nitric oxide (NO). RNS have been shown to modify cysteine and tyrosine residues $(15,22)$. Products of RNS such as lung 3-nitrotyrosine, lung DNP-derivatized protein, lung inducible NOS, and plasma nitrates/nitrites significantly increase after burn and smoke inhalation injury in the ovine model $(8,31,37)$. Lung interleukin- 8 expression significantly increases and $\mathrm{PaO}_{2} / \mathrm{FiO}_{2}$ ratios are significantly decreased after injury (31).

Antioxidants, such as vitamin E, attenuate the damage from oxidative and nitrosative stress. Alpha-tocopherol (a-T) is the major chain-breaking antioxidant in biological membranes. The term 'vitamin E' includes four tocopherols (alpha-, beta-, gamma-, and delta-) and four tocotrienols (alpha-, beta-, gamma-, and delta-) $(19,28)$. The different forms of vitamin $\mathrm{E}$ vary in the number and location of the ring methyl substituents on the chromanol ring (28). The two principal vitamin E forms found in human and animal diets are a-T and g-T (45). a$\mathrm{T}$ is an ROS scavenger, and $\mathrm{g}-\mathrm{T}$ scavenges both ROS and RNS, thus is a more effective radical scavenger (6).

The pulmonary function and pathophysiology of acute lung injury secondary to burn and smoke inhalation have been well studied in our large animal model, particularly within 48 hours after injury (11-13, 34-36). In our previous studies, we have demonstrated that after burn and smoke inhalation injury in the ovine model, most of the oxidative and nitrosative damage occurred in the lung (13). After 48 hours, we found that the bronchopulmonary damage from the injury preceded the systemic injury (13) and that the animals showed signs of ARDS, including deteriorated gas exchange, massive airway obstruction, pulmonary edema, and excessive production of ROS and RNS. a-T nebulization into the airway minimized these injuries (18). However, there are few studies that focus on the recovery phase of pulmonary function after burn and smoke inhalation (18). In order to evaluate the outcomes of specific therapies, their effects in the late and recovery stages of the lung must be demonstrated.

The mechanisms that induce pulmonary pathophysiology in burned patients are unknown. To date, there are no studies that report the relationship between pulmonary pathophysiology and nitrosative stress in large animals after burn and inhalation injury, after 96 hours. The well-established ovine model is clinically relevant because of similarities between human and ovine pulmonary physiology. We hypothesized that pulmonary changes associated with 
the acute phase of burn and smoke inhalation injury were caused by increased oxidative and nitrosative stress and that these would be ameliorated by g-T nebulization.

\section{MATERIALS AND METHODS}

\section{Animal Care and Use}

This study was approved by the Animal Care and Use Committee of the University of Texas Medical Branch and conducted in compliance with the guidelines of the National Institutes of Health and of the American Physiology Society for the care and the use of laboratory animals. The studies were completed at UTMB's Investigative Intensive Care Unit, which is accredited by the Association for the Assessment and Accreditation of Laboratory Animal Care (AAALAC).

\section{Animal Model}

The acute, 24-96 hr model of this burn and inhalation injury has previously been described in detail (36). The animals in the current 96-hour study were prepared in a similar manner. Briefly, 14 adult female Merino sheep (body weight, 30-40 kg) were surgically prepared under isoflurane anesthesia with a right femoral artery catheter (Intracath, 16GA, 24IN, Becton Dickinson Vascular Access, Sandy, UT), a thermodilution catheter (Model 131F7, Edwards Lifesciences LLC, Irvine, CA), and a left atrial catheter (0.062 in. ID, 0.125 in. OD; Dow Corning, Midland, MI). After a 7-day recovery period with free access to food and water, sheep were randomly divided into two groups: control (injured, nebulized with ethanol; $n=5$ ), and g-T (injured, nebulized with gamma-tocopherol; $n=6$ ). All animals were sacrificed after 96 hours.

\section{Burn and Smoke Inhalation Injury}

Animals were anesthetized with isoflurane and given flame burn ( $40 \%$ total body surface area [TBSA], third degree) and inhalation injury ( 48 breaths of cotton smoke, $\left.<40^{\circ} \mathrm{C}\right)$. The arterial carboxyhemoglobin $(\mathrm{COHb})$ level was determined immediately after the smoke inhalation. The animals were excluded if the highest arterial $\mathrm{COHb}$ was below $60 \%$, above $90 \%$, or if the temperature of insufflated smoke exceeded $40^{\circ} \mathrm{C}$. After the burn and smoke inhalation injury, all sheep were awakened and placed on a ventilator with positive end expiratory pressure set to $5 \mathrm{~cm} \mathrm{H}_{2} \mathrm{O}$ and tidal volume maintained at $15 \mathrm{~mL} / \mathrm{kg}$. The sheep were ventilated (Servo Ventilator 300, Siemens-Elema AB, Sweden) with $100 \%$ oxygen for the first $3 \mathrm{hrs}$ after injury for rapid clearance of $\mathrm{CO}$, to reduce their carboxyhemoglobin. Following this procedure, the fraction of inspired oxygen $\left(\mathrm{FiO}_{2}\right)$ was adjusted according to blood gas analysis to maintain $\mathrm{Pa}_{\mathrm{O} 2}$ above $80 \mathrm{~mm} \mathrm{Hg}$. Respiratory rate was initially set at 20 breaths/minute and thereafter adjusted to keep $\mathrm{Pa}_{\mathrm{CO} 2}$ between $25-35 \mathrm{~mm} \mathrm{Hg}$. All sheep were resuscitated with Ringer's solution, using the formula $4 \mathrm{~mL} / \mathrm{kg} / \%$ burned body surface for $24 \mathrm{hrs}$ and $2 \mathrm{~mL} / \mathrm{kg} / \%$ burned body surface from 24 to 48 hours. After 48 hours, the animals were weaned from the ventilator if the $\mathrm{PaO}_{2} / \mathrm{Fio}_{2}$ was above 250 (Figure 1).

\section{Vitamin E Nebulization}

Sheep in the vitamin E treatment group were nebulized with gamma-tocopherol using a technique that was developed in our laboratory (18). Briefly, the technique uses a novel viscous liquid nebulization nozzle and control that was adapted to a Siemans Servo 300 Ventilator. An aqueous solution of 33.3\% gamma-tocopherol (d-Gamma Tocopherol 90, Lot \#7801, Tama Biochemical, Japan), which contained $950 \mathrm{mg} / \mathrm{g}$ of $\mathrm{g}-\mathrm{T}$ and $40 \mathrm{mg} / \mathrm{g}$ of a-T, was mixed (w/w) with 66.6\% anhydrous ethanol (95\%, Pharmco-AAPER, Louisville, KY). In the nebulization control group, a solution of $33.3 \%$ sterile water and $66.6 \%$ ethanol $(\mathrm{w} / \mathrm{w})$ was substituted for the tocopherol mixture. The solutions were delivered into the $0.203 \mathrm{~mm}$ 
fluid channel nebulizing nozzle with a syringe pump at a rate of $0.071 \mathrm{~mL} / \mathrm{hr}$ for 45 hours (3.2 $\mathrm{mL}$ total), delivering about 1 gram of tocopherol over the treatment period. The animals were treated with gamma-tocopherol nebulization or water/ethanol 3 hours after the burn and smoke inhalation injury up to 48 hours after the injury.

\section{Measured Cardiopulmonary Variables}

The cardiopulmonary variables were not documented until the animals were fully awake and standing. The pulmonary shunt fraction was calculated by the following equation: $\mathrm{Q}_{S} / \mathrm{Q}_{t}=$ $\mathrm{C}_{\mathrm{A}} \mathrm{O}_{2}-\mathrm{C}_{\mathrm{a}} \mathrm{O}_{2} / \mathrm{C}_{\mathrm{A}} \mathrm{O}_{2}-\mathrm{C}_{\mathrm{V}} \mathrm{O}_{2}$. Arterial and mixed venous blood was used to measure the $\mathrm{PaO}_{2} / \mathrm{FiO}_{2}$ ratio, and it was determined using a blood gas analyzer (Model IL Synthesis 15, Instrumentation Laboratory, Lexington, MA). Peak and pause pressures were recorded every 6 hours.

\section{Lung Histology and Scoring}

The protocol for lung histology and scoring has previously been described in detail (7). Briefly, a 1-cm transverse slice was taken through the middle of the lower lobe of the right ovine lung and injected with $10 \%$ buffered formalin at necropsy. The tissue was then immersed in fixative for 3 to 5 days and sampled into blocks. Following standardized paraffin-embedding protocols, 4- $\mu \mathrm{m}$ sections were obtained and stained with hematoxylin and eosin. An experienced pathologist scored the slides without knowledge of the experimental group. Hemorrhage was scored subjectively for the degree of the abnormality, using $0=$ absent, $1=$ mild, $2=$ mild to moderate, $3=$ moderate, $4=$ moderate to severe, and $5=$ severe. Edema and the extent of neutrophils in alveoli, on the other hand, were scored according to the percentage of the section occupied by the each, using $0=$ none, $1=1 \%$ to $20 \%, 2=20 \%$ to $40 \%, 3=40 \%$ to $60 \%, 4=60 \%$ to $80 \%$, and $5=80 \%$ to $100 \%$.

\section{Lung Alpha- and Gamma-Tocopherol Measurement}

The methods for determining lung a-T and $\mathrm{g}$ - $\mathrm{T}$ have previously been described in detail (28). All results are expressed as $\mathrm{nmol} / \mathrm{g}$ and are corrected for wet/dry ratios (see below).

\section{Lung Bloodless Wet-to-Dry Weight Ratio}

The right lower lobe of the lung was harvested for measurement of wet-to-dry weight ratio and was corrected for the content of blood in a procedure described by Pearce and colleagues (27). The wet-to-dry weight ratio was obtained by dividing the wet weight by the final weight of the dried lungs.

\section{Lung Obstruction Measurements of Bronchus and Bronchioles}

A one-centimeter thick section of the lung was taken from the lower right lobe perpendicular to the right main bronchus. It was fixed by injection of $10 \%$ formalin, the immersed in formalin, embedded in paraffin, and cut into $4 \mu \mathrm{m}$ sections onto coded slides. Each airway was classified as a bronchus, bronchiole or terminal bronchiole. Three individuals unaware of the treatment group evaluated each of the bronchi (15) and bronchioles (50) to determine the mean obstruction score for each sheep using masked slides. The percentage of total airway lumen obstructed by casts was determined from 0 to 100\%, as described by Cox and colleagues (7).

\section{Lung Poly (ADP-ribose) Polymerase Activation}

PARP activation in the lung was measured by western blot. Lung samples $(100 \mathrm{mg})$ were homogenized in ice-cold buffer (50 mM HEPES pH=7.4, $150 \mathrm{mM}$ sodium chloride, $1.5 \mathrm{mM}$ magnesium chloride, $1 \mathrm{mM}$ EDTA, $1 \%$ triton, $10 \%$ glycerol, protease inhibitor cocktail 1:100, sodium metavanadate 1:100; all materials were purchased from Sigma-Aldrich Co., 
St. Louis, Mo, USA.). After centrifugation $(14000 \times \mathrm{g}, 5$ minutes $)$, the supernatant was collected. Proteins were resolved by electrophoresis using polyacrylamide gels (Invitrogen, Carlsbad, CA, USA), after mixing with Laemmli loading buffer with $10 \%$ mercaptoethanol. Separated proteins were transferred to a nitrocellulose membrane (Biorad, Hercules, Ca, USA). Membranes were incubated for two hours in blocking buffer (5\% non-fat dry milk in PBS). After blocking, membranes were probed overnight at $4^{\circ} \mathrm{C}$ using antibody recognizing the poly (ADP-ribose) polymer antigen (polyclonal, Trevigen, Gaithersburg, MD, USA). Anti-rabbit horseradish peroxidase-conjugated antibody was used as a secondary antibody (1:1000, Southern Biotech, Birmingham, AL). The antibody-antigen complexes were visualized by enhanced chemiluminescence by Syngene gel documentation system (Syngene, Frederick, MD), and the results were quantified by GeneTools from Syngene.

\section{Statistical Analysis}

Statistical significances of the comparisons were determined using a two-factor (treatment and time) analysis of variance with repeated measures. Fisher's least significant difference procedure, with Bonferroni's adjustment for number of comparisons, was used for the multiple comparisons (or post hoc analysis). The differences between groups in concentration of tocopherols, wet-to-dry weight ratio, obstruction score, and PAR were evaluated by means of Student's unpaired $t$ test. A value of $p<0.05$ was considered to be statistically significant.

\section{RESULTS}

\section{Carboxyhemoglobin Concentrations, Injury, and Survival}

The arterial COHb levels were measured immediately after smoke exposure (mean $\pm \mathrm{SD}$ ), and 3 of the 14 sheep were excluded for low levels. There were no significant differences in arterial $\mathrm{COHb}$ between the $\mathrm{g}-\mathrm{T}(69.1 \pm 2.4 \%)$ and the control $(72.9 \pm 1.3 \%)$ groups. All animals survived for 96 in the g-T group, and 1 of the 5 control sheep died at 64 hours after injury.

\section{Weaning from Mechanical Ventilation}

All g-T nebulization animals were weaned from ventilator and extubated by $96 \mathrm{~h}$ post injury, while none of control animals were completely weaned (Table 1). Two of the control animals never attained the criteria for weaning, while the other three control animals could not begin to be weaned until $70-90 \mathrm{~h}$ post injury. In contrast, animals treated with g-T nebulization were able to start weaning significantly earlier, and their tracheostomy tubes could be removed after T-piece trials.

Decreases in septal edema were found between animals with and without vitamin $\mathrm{E}$ treatment $(2.71 \pm 0.47$ control vs $1.42 \pm 0.43 \mathrm{~g}$ - $\mathrm{T}$, data not shown). Decreases were also seen in alveolar edema ( $1.05 \pm 0.48$ control vs $0.29 \pm 0.10 \mathrm{~g}$-T, data not shown), as well as in polymorphonuclear cells in the alveoli $(0.50 \pm 0.29$ control vs $0.17 \pm 0.08 \mathrm{~g}$-T, data not shown), septal cell thickening ( $1.60 \pm 0.19$ control vs $1.25 \pm 0.14 \mathrm{~g}-\mathrm{T}$, data not shown), and hemorrhage $(0.30 \pm 0.24$ control vs $0.04 \pm 0.04 \mathrm{~g}-\mathrm{T}$, data not shown $)$.

\section{Gamma- and Alpha-Tocopherol Significantly Increased after Injury with Vitamin E Treatment compared to Injured Sheep}

The level of gamma-tocopherol in normal ovine lungs was $0.27 \pm 0.05 \mathrm{nmol} / \mathrm{g}$ (18). Smoke inhalation resulted in depletion in this particular form of vitamin E (38). The sheep were nebulized with a solution of $950 \mathrm{mg} / \mathrm{g}$ of $\mathrm{g}-\mathrm{T}$ and $40 \mathrm{mg} / \mathrm{g}$ of a-T, which resulted in increases in lung of both g-T ( $p<0.05$; Figure 2A) and a-T concentrations $(p<0.05$, Figure 
2B). However, nebulization did not cause a statistically significant change in hepatic levels of either g-T or a-T (Figure 2C-D).

\section{Gamma-Tocopherol Nebulization Significantly Decreased Pulmonary Shunt Fraction, Peak Pressure and Pause Pressure, and Significantly Increased $\mathrm{PaO}_{2} / \mathrm{FiO}_{2}$ Ratio after 96 Hours in Injured Sheep}

After injury, the $\mathrm{PaO}_{2} / \mathrm{FiO}_{2}$ levels of control animals fell below $200 \mathrm{mmHg}$, which is the threshold for the diagnosis of the acute respiratory distress syndrome (ARDS). The $\mathrm{PaO}_{2} /$ $\mathrm{FiO}_{2}$ did not fall to the same extent in the sheep treated with gamma-tocopherol $(p<0.05$ at $30,36,42,48$, and 60 hours after injury; Figure 3A). It was difficult to compare $\mathrm{PaO}_{2} / \mathrm{FiO}_{2}$ levels in each group $48 \mathrm{~h}$ after injury because the control animals remained on the ventilator for 96 hours. Similarly, the pulmonary shunt was not as high in the sheep treated with tocopherol ( $p<0.05$ after 42 hours post-injury; Figure 3B). Ventilatory peak and pause pressures are elevated by combined burn and smoke injury. These variables did not rise to the same extent with gamma-tocopherol ( $p<0.05$ after 42 hours post-injury; Figure 4A-B).

\section{Lung Obstruction of the Bronchioles and Wet-to-Dry Weight Ratio Significantly Decreased with Vitamin E Treatment after Burn and Smoke Inhalation Injury}

We observed an increase in lung wet-to-dry weight ratio, as well as marked obstruction of bronchioles, due to combined burn and smoke inhalation. g-T treatment caused a significant decrease in pulmonary edema and obstruction of the bronchioles compared to untreated animals $(p<0.05$, Figure 5A-B).

\section{Poly (ADP Ribose)-Polymerase (PARP) Activation Significantly Decreased with Vitamin E Treatment after Burn and Smoke Inhalation Injury}

PARP is a constitutive enzyme that is activated by DNA strand breaks secondary to oxidative stress. PARP activity was determined by measuring PAR protein, the product or the reaction $(1,41)$. PAR was significantly increased following burn and inhalation injury, and treatment with gamma-tocopherol markedly reduced PARP activation, as assessed by quantification of tissue levels of PAR (Figure 6).

\section{DISCUSSION}

In a previous study by our laboratory, the nebulization of g-T attenuated burn and smoke inhalation-induced pathological changes and improved pulmonary function after 48 hours (18). In our current study, we have nebulized a larger concentration of g-T and analyzed additional variables in the 96-hour late and recovery stage of burn and smoke inhalation such as ventilator weaning, peak and pause pressures, and shunt fraction. Nebulization with gamma-tocopherol into the lungs of sheep with a burn and smoke inhalation injury ameliorated the damage observed in those nebulized with the vehicle. Specifically, g-Ttreatment facilitated more effective pulmonary gas exchange $\left(\mathrm{PaO}_{2} / \mathrm{FiO}_{2}\right.$ and pulmonary shunt fraction) and led to less obstruction in the bronchi and bronchioles of the lung, and less edema in the lungs (bloodless wet-to-dry ratio). We hypothesized that pulmonary changes associated with the acute phase of burn and smoke inhalation injury are caused by increased oxidative and nitrosative stress. We tested our hypothesis by delivering gammatocopherol into the airway to act as an anti-oxidant, scavenge ROS and RNS, and attenuate pulmonary pathophysiology after combined burn and smoke inhalation injury.

We have reported that NO generated from inducible nitric oxide synthase (NOS) has an important role in the changes in both systemic and pulmonary microvascular permeability, which follow combined burn and smoke inhalation injury $(9,23)$. Burn and smoke inhalation injury is associated with a systemic inflammatory response, and increased levels 
of RNS and ROS in the lung $(13,36)$. Peroxynitrite is a strong oxidant, and a nitrating and nitrosating agent, that can readily trigger DNA single-strand breakage and induce poly (ADP-ribose) polymerase (PARP) activation $(32,44)$. Intracellular NAD and ATP levels are depleted as a consequence of PARP activation (46). In addition, PARP has been shown to be involved in the regulation of inflammatory processes, being functionally associated with nuclear factor- $\mathrm{kB}(\mathrm{NF}-\mathrm{\kappa B})(40)$. g-T and a-T are scavengers of RNS and ROS. Although g-T and a-T are both potent lipophilic antioxidants, $\mathrm{g}-\mathrm{T}$ has a unique function. $\mathrm{g}-\mathrm{T}$ is a more effective RNS scavenger than a-T because it has an unsubstituted 5-position on the chromanol ring (10).

Lipid peroxidation markers have been measured by our group and have significantly increased in survivors of burn injury compared to nonsurvivors. Malondialdehyde, which is a large mutagenic ROS, has been previously measured in sheep with burn and smoke inhalation injury with and without vitamin E. It significantly increased in sheep without vitamin $\mathrm{E}$ treatment. In our present study, lung oxidative stress was indirectly measured by analyzing g-T and a-T concentrations by HPLC. Lung g- $\mathrm{T}$ and a-T concentrations significantly increased after the nebulization of vitamin $\mathrm{E}$ (Figure 2.1). The plasma a-T and $\mathrm{g}$-T concentrations did not change dramatically because the nebulized $\mathrm{E}$ does not cross into the circulation (data not shown). The lung data illustrates that our novel lipid nebulization device that was used in the present study can aerosolize viscous lipid materials effectively. It creates $2.5-5.0 \mu \mathrm{m}$ droplets of vitamin $\mathrm{E}$ and is synchronized with the ventilator to deliver it only during the inspiratory cycle (18).

A previous study from our laboratory showed that the increases in oxidative and nitrosative stress markers were significantly decreased in injured sheep treated with a mixed a-T and gT solution and sacrificed after 48 hours $(610 \mathrm{mg} / \mathrm{g}$ of g-T and $91 \mathrm{mg} / \mathrm{g}$ of a-T nebulized over 48 hours) $(9,18)$. In the present study, we nebulized a larger amount of g-T $(950 \mathrm{mg} / \mathrm{g}$ of g$\mathrm{T}$ and $40 \mathrm{mg} / \mathrm{g}$ of a-T) from 3 to 48 hours after injury and sacrificed the animals after 96 hours. The larger concentration of $\mathrm{g}$ - $\mathrm{T}$ attenuated the changes not only during the subsequent $48 \mathrm{~h}$ period but also the late and recovery stage after 96 hours. Additional differences between the present and previously reported studies are that all of the g-T treated animals could be weaned from the ventilator, while none of the control animals were weaned (Figure 1), and the shunt fraction and peak and pause pressures were significantly improved (Figures 3B, 4).

Another difference between our previously reported study (18) and the present study is that ethanol was used as the vehicle carrier instead of flaxseed oil. $100 \% \mathrm{~g}$-T is a viscous lipid material and difficult to aerosolize using our novel lipid nebulization without a carrier. Ethanol has been reported as a low-toxicity solvent for inhalation delivery (33) and has been used in nebulized and metered dose inhalers and formulations for human use (4). Therefore, we selected ethanol as a vehicle for nebulization with $\mathrm{g}$-T. There are reports that nebulization with ethanol reduces the pathophysiology of pulmonary edema perhaps through its effects as an anti-foam agent $(2,21)$. Sisson et.al. reported that brief exposure to a mild concentration of ethanol may enhance mucociliary clearance, stimulate bronchodilation, and attenuate the airway inflammation and injury observed in asthma and chronic obstructive pulmonary dysfunction (COPD) (33). Furthermore, Oldenburg et al. reported that brief ethanol exposure prevents methacholine-stimulated rat airway smooth muscle cell contraction in vivo (26). Although tocopherol was very effective in ablating many of the pathophysiological changes noted with inhalation injury, the control group that received ethanol alone appeared to have less of an injury in comparison to our past studies. Our previous findings in the sheep model of burn and smoke inhalation have shown that $1.1 \mathrm{~mL}$ ethanol nebulized into the lung over a 24 hour period did not worsen lung function or mortality (which is usually $60-75 \%)(14,17)$. Additionally, in our previous study $(18)$, g-T 
improved wet-to-dry weight ratios and obstruction scores significantly compared to the saline control, but not compared to the appropriate flaxseed oil control. The flaxseed oil itself restored $\mathrm{g}$ - $\mathrm{T}$ levels to baseline values. Thus, the omission of the flaxseed oil carrier allows the extent of the significant differences from the control group to be observed much more clearly.

Gamma-tocopherol nebulization significantly reduced the wet/dry weight ratio in lung tissue (Figure 5A). Nebulization with the g-T solution for the first $48 \mathrm{~h}$ increased lung g-T levels at $96 \mathrm{~h}$ post-injury more than 100 -fold. a-T concentrations were also significantly higher in the g-T group as compared to the control group (Figure 2A). Since the g-T contains some a-T, it is unclear whether the increase was due to the administration of the solution, or whether the supply of g-T protected endogenous a-T from oxidation. The g-T nebulization decreased severe signs of acute lung injury as evidenced by deteriorated pulmonary gas change, massive airway obstruction, pulmonary edema, and PARP activation at $96 \mathrm{~h}$ post-injury. It was difficult to compare pulmonary function evidenced by $\mathrm{Pa}_{2} / \mathrm{FiO}_{2}$ ratio in each group after $48 \mathrm{~h}$ post-injury, because only control animals were supported by mechanical ventilation between 48 and $96 \mathrm{~h}$ after injury. Therefore, the weaning process was compared between groups to show the effects of treatment in the recovery stage. The weaning could be initiated significantly earlier in the g-T group after $48 \mathrm{~h}$ post injury compared to the control group. The tracheostomy tube of all g-T nebulization animals could be removed within $96 \mathrm{~h}$ post injury, whereas none of the control animals could be completely weaned nor their tracheostomy tubes removed. In human intensive care units, prolonged intubation is known to be associated with ventilator-induced lung injury, ventilator-associated pneumonia, patient discomfort, and the need for high dose sedation $(3,5,42)$. Quicker weaning from the mechanical ventilator and removal of the endotracheal tube are expected to reduce these problems.

In summary, we report that burn and smoke inhalation injury significantly reduces lung alpha- and gamma-tocopherol concentrations and increases markers of pulmonary pathophysiology such as deteriorated pulmonary gas exchange, increased peak and pause pressures, massive airway obstruction, and increased pulmonary edema, while nebulization with gamma-tocopherol attenuated the injury, improved pulmonary oxygenation, and markedly reduced ventilator time. Pulmonary gamma-tocopherol delivery in ethanol may be a safe, novel, and effective treatment of patients with the acute phase of burn and smoke inhalation.

\section{Acknowledgments}

This work was supported by Grants GM66312-01 and GM60668 from the National Institute of General Medical Science, and Grants 8630, 8520, 8954, 84060 and 8450 from the Shrine Hospitals for Children (SHC).

The authors would like to thank the staff of the Investigational Intensive Care Unit at the University of Texas Medical Branch for their valuable assistance, especially C. Moncebaiz, Y. Larson, J. Jinkins, T. Walker, and C. Hallum.

\section{BIBLIOGRAPHY}

1. Bartha E, Solti I, Kereskai L, Lantos J, Plozer E, Magyar K, Szabados E, Kalai T, Hideg K, Halmosi R, Sumegi B, Toth K. PARP inhibition delays transition of hypertensive cardiopathy to heart failure in spontaneously hypertensive rats. Cardiovasc Res. 2009; 83:501-510. [PubMed: 19443425]

2. Boxman D. Alcohol vapor in the emergency treatment of acute pulmonary edema. Journal of the American Osteopathic Association. 1958; 57:659-661. [PubMed: 13549273]

3. Brochard L, Mancebo J, Elliott MW. Noninvasive ventilation for acute respiratory failure. Eur Respir J. 2002; 19:712-721. [PubMed: 11999003] 
4. Choi WS, Murthy GG, Edwards DA, Langer R, Klibanov AM. Inhalation delivery of proteins from ethanol suspensions. Proc Natl Acad Sci U S A. 2001; 98:11103-11107. [PubMed: 11562495]

5. Cook D, De Jonghe B, Brochard L, Brun-Buisson C. Influence of airway management on ventilatorassociated pneumonia: evidence from randomized trials. JAMA. 1998; 279:781-787. [PubMed: 9508156]

6. Cooney RV, Franke AA, Harwood PJ, Hatch-Pigott V, Custer LJ, Mordan LJ. Gamma-tocopherol detoxification of nitrogen dioxide: superiority to alpha-tocopherol. Proc Nat Acad Sci (USA). 1993; 90:1771-1175. [PubMed: 8446589]

7. Cox RA, Burke AS, Soejima K, Murakami K, Katahira J, Traber LD, Herndon DN, Schmalstieg FC, Traber DL, Hawkins HK. Airway obstruction in sheep with burn and smoke inhalation injuries. Am J Respir Cell Mol Biol. 2003; 29:295-302. [PubMed: 12936906]

8. Cox RA, Jacob S, Oliveras G, Murakami K, Enkhbaatar P, Traber L, Schmalstieg FC, Herndon DN, Traber DL, Hawkins HK. Pulmonary expression of nitric oxide synthase isoforms in sheep with smoke inhalation and burn injury. Exp Lung Res. 2009; 35:104-118. [PubMed: 19263280]

9. Demling R, Ikegami K, LaLonde C. Increased lipid peroxidation and decreased antioxidant activity correspond with death after smoke exposure in the rat. J Burn Care Rehabil. 1995; 16:104-110. [PubMed: 7775502]

10. Devaraj S, Traber MG. Gamma-tocopherol, the new vitamin E? Am J Clin Nutr. 2003; 77:530531. [PubMed: 12600839]

11. Enkhbaatar P, Cox RA, Traber LD, Westphal M, Aimalohi E, Morita N, Prough DS, Herndon DN, Traber DL. Aerosolized anticoagulants ameliorate acute lung injury in sheep after exposure to burn and smoke inhalation. Crit Care Med. 2007; 35:2805-2810. [PubMed: 18074480]

12. Enkhbaatar P, Esechie A, Wang J, Cox RA, Nakano Y, Hamahata A, Lange M, Traber LD, Prough DS, Herndon DN, Traber DL. Combined anticoagulants ameliorates acute lung injury in sheep after burn and smoke inhalation. Clin Sci (Lond). 2008; 114:321-329. [PubMed: 17927568]

13. Enkhbaatar P, Murakami K, Shimoda K, Mizutani A, Traber L, Phillips GB, Parkinson JF, Cox R, Hawkins H, Herndon D, Traber D. The inducible nitric oxide synthase inhibitor BBS-2 prevents acute lung injury in sheep after burn and smoke inhalation injury. Am J Respir Crit Care Med. 2003; 167:1021-1026. [PubMed: 12663341]

14. Esechie A, Kiss L, Olah G, Horvath EM, Hawkins HK, Szabo C, Traber DL. Protective effect of hydrogen sulfide in a murine model of combined burn and smoke inhalation-induced acute lung injury. Clin Sci (Lond). 2008; 115:91-97. [PubMed: 18315525]

15. Forman HJ, Fukuto JM, Torres M. Redox signaling: thiol chemistry defines which reactive oxygen and nitrogen species can act as second messengers. Am J Physiol Cell Physiol. 2004; 287:C246256. [PubMed: 15238356]

16. Gore DC, Hawkins HK, Chinkes DL, Chung DH, Sanford AP, Herndon DN, Wolf SE. Assessment of adverse events in the demise of pediatric burn patients. J Trauma. 2007; 63:814-818. [PubMed: 18090010]

17. Hamahata A, Enkhbaatar P, Hiroyuki S, Nozaki M, Traber DL. Effect of ablated bronchial blood flow on survival rate and pulmonary function after burn and smoke inhalation in sheep. Burns. 2009; 35:802-810. [PubMed: 19303716]

18. Hamahata A, Enkhbaatar P, Kraft ER, Lange M, Leonard SW, Traber MG, Cox RA, Schmalstieg FC, Hawkins HK, Whorton EB, Horvath EM, Szabo C, Traber LD, Herndon DN, Traber DL. gamma-Tocopherol nebulization by a lipid aerosolization device improves pulmonary function in sheep with burn and smoke inhalation injury. Free Radic Biol Med. 2008; 45:425-433. [PubMed: 18503777]

19. Kagan VE. Tocopherol stabilizes membrane against phospholipase A, free fatty acids, and lysophospholipids. Ann N Y Acad Sci. 1989; 570:121-135. [PubMed: 2698101]

20. Korkmaz A, Topal T, Oter S. Pathophysiological aspects of cyclophosphamide and ifosfamide induced hemorrhagic cystitis; implication of reactive oxygen and nitrogen species as well as PARP activation. Cell Biol Toxicol. 2007; 23:303-312. [PubMed: 17225077]

21. Luisada AA. Therapy of paroxysmal pulmonary edema by anti-foaming agents. Proc Soc Exp Biol Med. 1950; 74:215-217. [PubMed: 15430438] 
22. Negash S, Gao Y, Zhou W, Liu J, Chinta S, Raj JU. Regulation of cGMP-dependent protein kinase-mediated vasodilation by hypoxia-induced reactive species in ovine fetal pulmonary veins. Am J Physiol Lung Cell Mol Physiol. 2007; 293:L1012-1020. [PubMed: 17616649]

23. Nguyen TT, Cox CS Jr, Herndon DN, Biondo NA, Traber LD, Bush PE, Traber DL. Effects of manganese superoxide dismutase on lung fluid balance after smoke inhalation. J Appl Physiol. 1995; 78:2161-2168. [PubMed: 7665413]

24. Nguyen TT, Cox CS, Traber DL, Gasser H, Redl H, Schlag G, Herndon DN. Free radical activity and loss of plasma antioxidants, vitamin E, and sulfhydryl groups in patients with burns: the 1993 Moyer Award. J Burn Care Rehabil. 1993; 14:602-609. [PubMed: 8300695]

25. Nguyen, TT.; Herndon, DN.; Cox, CS.; Biondo, N.; Traber, LD.; Bush, PE.; Traber, DL. Effect of manganous superoxide dismutase on lung fluid balance after smoke inhalation injury. Proceedings of the American Burn Association; 1993. p. 31

26. Oldenburg PJ, Wyatt TA, Factor PH, Sisson JH. Alcohol feeding blocks methacholine-induced airway responsiveness in mice. Am J Physiol Lung Cell Mol Physiol. 2009; 296:L109-114. [PubMed: 18931055]

27. Pearce ML, Yamashita J, Beazell J. Measurement of pulmonary edema. Circ Res. 1965; 16:482488. [PubMed: 14289157]

28. Podda M, Weber C, Traber MG, Packer L. Simultaneous determination of tissue tocopherols, tocotrienols, ubiquinols, and ubiquinones. Journal of Lipid Research. 1996; 37:893-901. [PubMed: 8732789]

29. Pruitt, BA., Jr; Goodwin, CW.; Mason, AD, Jr. Epidemiology, demographic, and outcome characteristics of burn injury. In: Herndon, D., editor. Total Burn Care. Philadelphia: Saunders/ Elsevier; 2007. p. 16-32.

30. Saffle JR, Davis B, Williams P. Recent outcomes in the treatment of burn injury in the United States: a report from the American Burn Association Patient Registry. J Burn Care Rehabil. 1995; 16:219-232. discussion 288-219. [PubMed: 7673300]

31. Schmalstieg FC, Chow J, Savage C, Rudloff HE, Palkowetz KH, Zwischenberger JB. Interleukin-8, aquaporin-1, and inducible nitric oxide synthase in smoke and burn injured sheep treated with percutaneous carbon dioxide removal. ASAIO J. 2001; 47:365-371. [PubMed: 11482488]

32. Shimoda K, Murakami K, Enkhbaatar P, Traber LD, Cox RA, Hawkins HK, Schmalstieg FC, Komjati K, Mabley JG, Szabo C, Salzman AL, Traber DL. Effect of poly(ADP ribose) synthetase inhibition on burn and smoke inhalation injury in sheep. Am J Physiol Lung Cell Mol Physiol. 2003; 285:L240-249. [PubMed: 12626333]

33. Sisson JH. Alcohol and airways function in health and disease. Alcohol. 2007; 41:293-307. [PubMed: 17764883]

34. Soejima K, Schmalstieg FC, Sakurai H, Traber LD, Traber DL. Pathophysiological analysis of combined burn and smoke inhalation injuries in sheep. AmJPhysiolLung Cell MolPhysiol. 2001; 280:L1233-L1141.

35. Soejima K, Schmalstieg FC, Traber LD, Szabo C, Salzman A, Traber DL. Role of nitric oxide in myocardial dysfunction after combined burn and smoke inhalation injury. Burns. 2001; 27:809815. [PubMed: 11718983]

36. Soejima K, Traber LD, Schmalstieg FC, Hawkins H, Jodoin JM, Szabo C, Szabo E, Varig L, Salzman A, Traber DL. Role of nitric oxide in vascular permeability after combined burns and smoke inhalation injury. Am J Respir Crit Care Med. 2001; 163:745-752. [PubMed: 11254534]

37. Sousse LE, Yamamoto Y, Enkhbaatar P, Rehberg SW, Wells SM, Leonard S, Traber MG, Yu YM, Cox RA, Hawkins HK, Traber LD, Herndon DN, Traber DL. Acute Lung Injury-Induced Collagen Deposition is Associated with Elevated Asymmetric Dimethylarginine and Arginase Activity. Shock. 2010; 35:282-288. [PubMed: 20938379]

38. Sousse LE, Yamamoto Y, Enkhbaatar P, Rehberg SW, Wells SM, Leonard S, Traber MG, Yu YM, Cox RA, Hawkins HK, Traber LD, Herndon DN, Traber DL. Acute Lung Injury-Induced Collagen Deposition is Associated with Elevated Asymmetric Dimethylarginine and Arginase Activity. Shock. 2011; 35:282-288. [PubMed: 20938379] 
39. Suzuki M, Aikawa N, Kobayashi K, Higuchi R. Prognostic implications of inhalation injury in burn patients in Tokyo. Burns. 2005; 31:331-336. [PubMed: 15774289]

40. Szabo C. Potential role of the peroxynitrate-poly(ADP-ribose) synthetase pathway in a rat model of severe hemorrhagic shock. Shock. 1998; 9:341-344. [PubMed: 9617883]

41. Tapodi A, Debreceni B, Hanto K, Bognar Z, Wittmann I, Gallyas F Jr, Varbiro G, Sumegi B. Pivotal role of Akt activation in mitochondrial protection and cell survival by poly(ADPribose)polymerase-1 inhibition in oxidative stress. J Biol Chem. 2005; 280:35767-35775. [PubMed: 16115861]

42. Terragni PP, Antonelli M, Fumagalli R, Faggiano C, Berardino M, Pallavicini FB, Miletto A, Mangione S, Sinardi AU, Pastorelli M, Vivaldi N, Pasetto A, Della Rocca G, Urbino R, Filippini C, Pagano E, Evangelista A, Ciccone G, Mascia L, Ranieri VM. Early vs late tracheotomy for prevention of pneumonia in mechanically ventilated adult ICU patients: a randomized controlled trial. JAMA. 2010; 303:1483-1489. [PubMed: 20407057]

43. Traber, DL.; Enkhabaatar, P. Thermal lung injury and acute smoke inhalation. In: Fischman, DA., editor. Fischman's pulmonary diseases and disorders. New York: McGraw-Hill Medical Publishing Company; 2008. p. 1053-1064.

44. Traber DL, Hawkins HK, Enkhbaatar P, Cox RA, Schmalstieg FC, Zwischenberger JB, Traber LD. The role of the bronchial circulation in the acute lung injury resulting from burn and smoke inhalation. Pulm Pharmacol Ther. 2007; 20:163-166. [PubMed: 16798035]

45. Traber MG. Vitamin E regulatory mechanisms. Annu Rev Nutr. 2007; 27:347-362. [PubMed: 17439363]

46. Virag L, Szabo C. The therapeutic potential of poly(ADP-ribose) polymerase inhibitors. Pharmacol Rev. 2002; 54:375-429. [PubMed: 12223530] 
WEANING FROM MECHANICAL VENTILATION

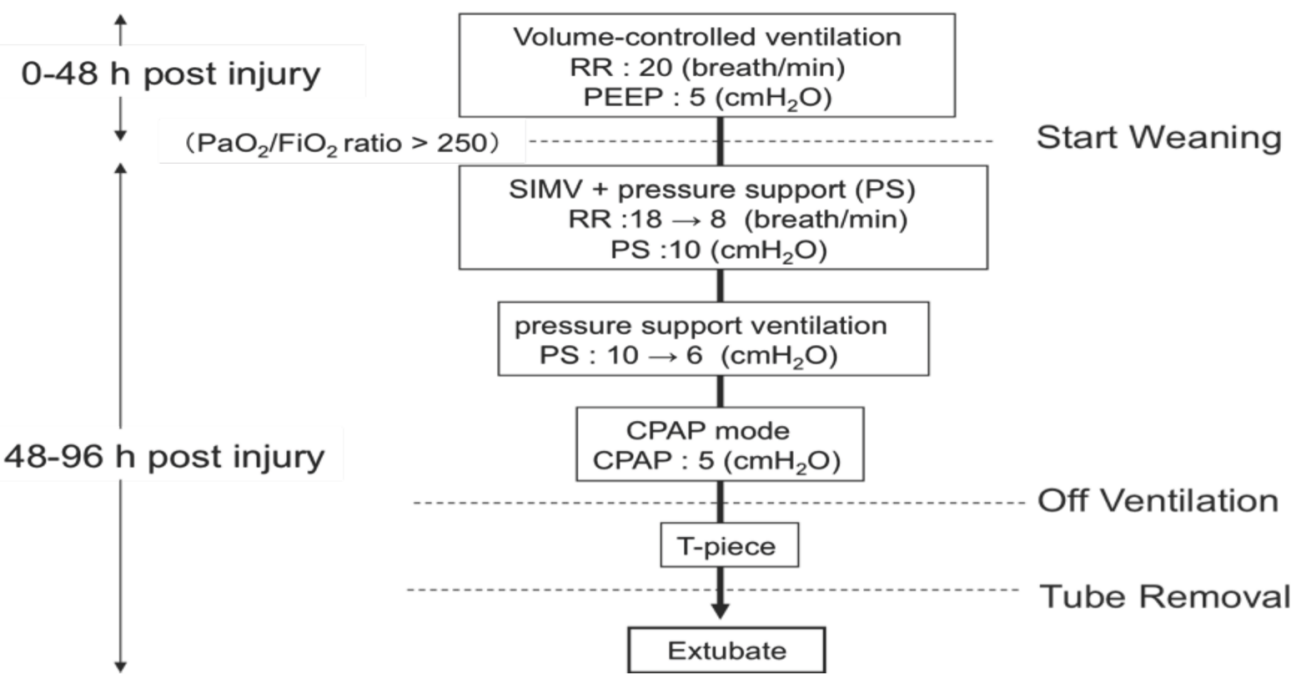

Figure 1.

Protocol for Weaning from Mechanical Ventilation. Weaning from ventilator was initiated if $\mathrm{PaO}_{2} / \mathrm{FiO}_{2}$ ratio is above 250 at 48 or more hours after injury. 
2A

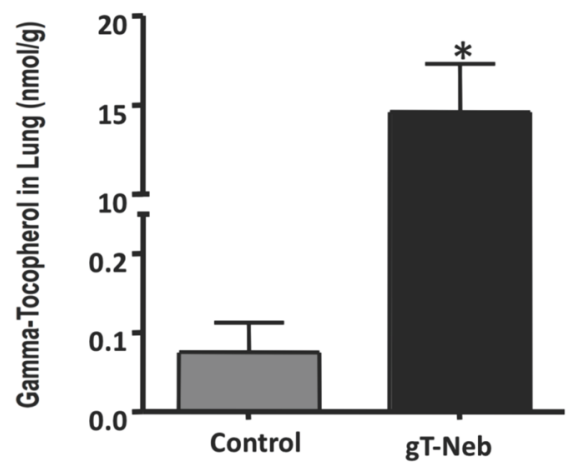

2B

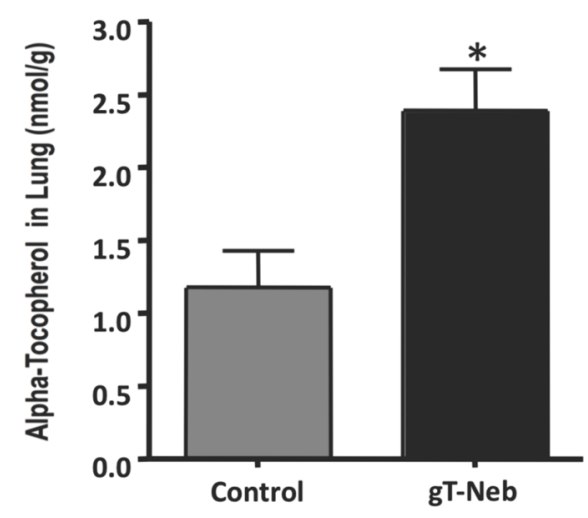




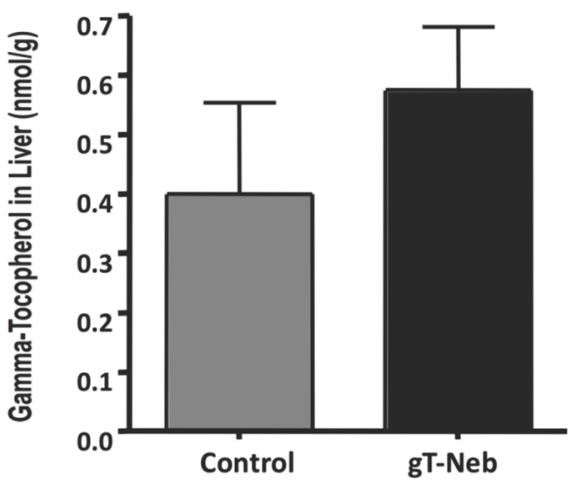

\section{D}

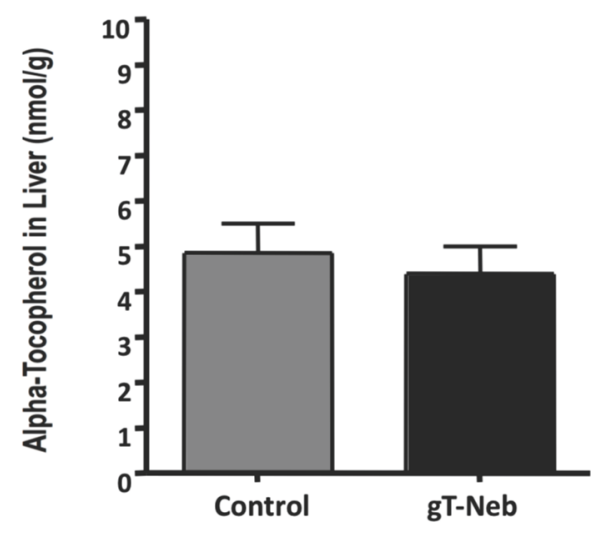

Figure 2.

Gamma- and Alpha-Tocopherol Concentrations after Burn and Smoke Inhalation Injury with and without Gamma-Tocopherol Nebulization. After a 40\% TBSA full thickness burn and a smoke inhalation injury, sheep were killed after 96 hours and lung homogenate was used to indirectly measure oxidative stress. Results were compared to injured animals that were nebulized with vitamin E. Oxidative stress was evaluated by measuring ROS and RNS scavenger gamma-tocopherol in the (A) lung and (C) liver, and ROS scavenger alphatocopherol in the (B) lung and (D) liver. Lung oxidative stress was attenuated post-injury with vitamin $\mathrm{E}$ treatment based on the associated increases in tocopherols. Data are shown as means \pm SEM. $* p<0.05$ versus injured animals sacrificed after 96 hours. 


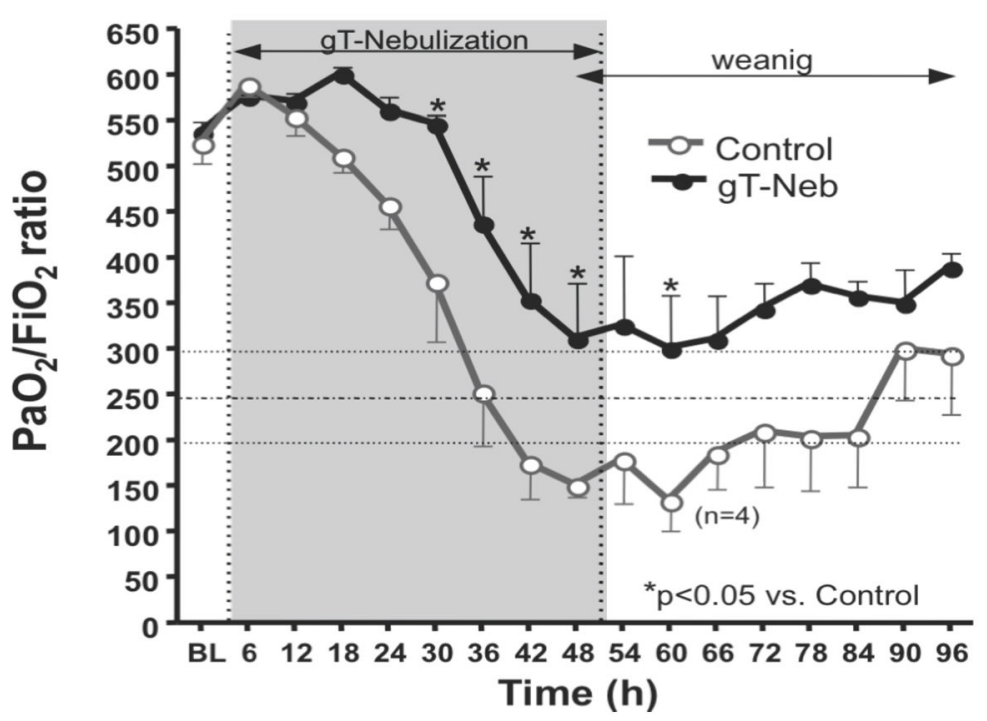

3B

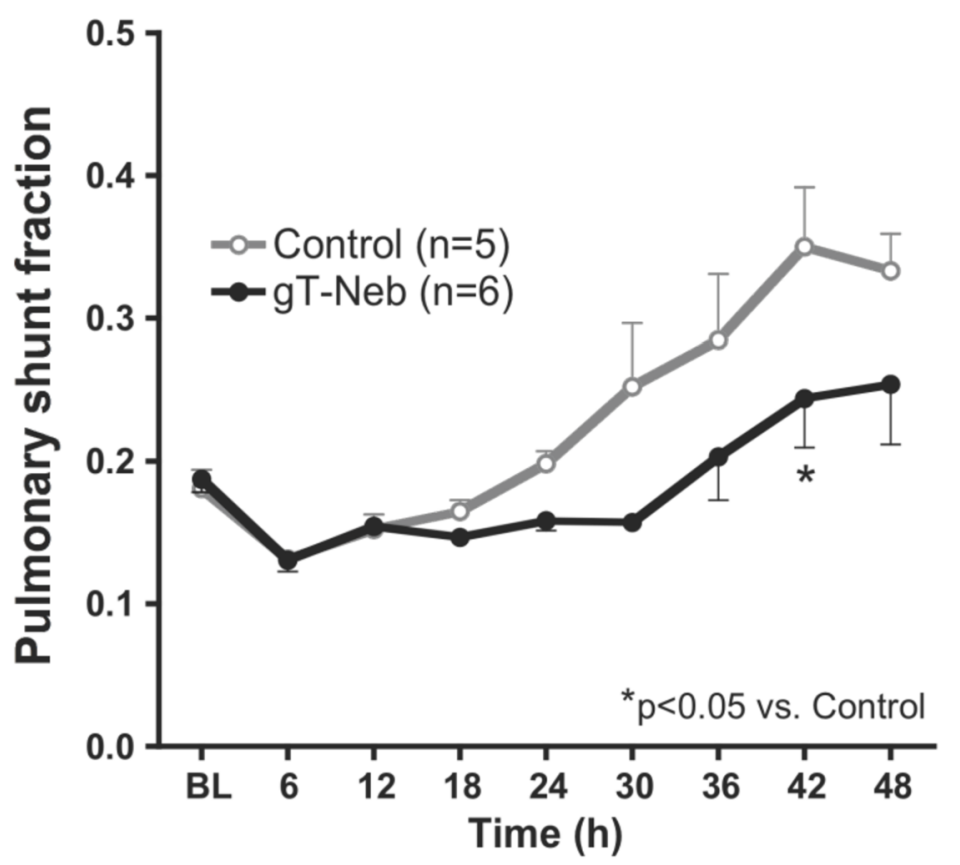

Figure 3. 
Pulmonary Gas Exchange after Burn and Smoke Inhalation Injury with and without Gamma-Tocopherol Nebulization. After a 40\% TBSA full thickness burn and a smoke inhalation injury, sheep were killed after 96 hours. Results were compared to injured animals that were nebulized with vitamin E. Pulmonary gas exchange was evaluated by measuring (A) $\mathrm{PaO}_{2} / \mathrm{FiO}_{2}$, and (B) pulmonary shunt fraction. Pulmonary gas exchange significantly improved with vitamin $E$ treatment. Data are shown as means \pm SEM. * $P<$ 0.05 versus injured animals sacrificed after 96 hours. 


\section{$4 \mathrm{~A}$}

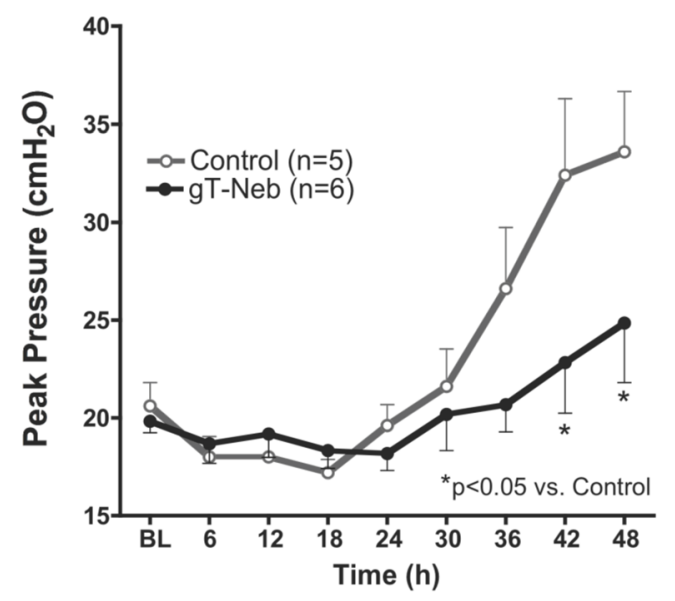

4B

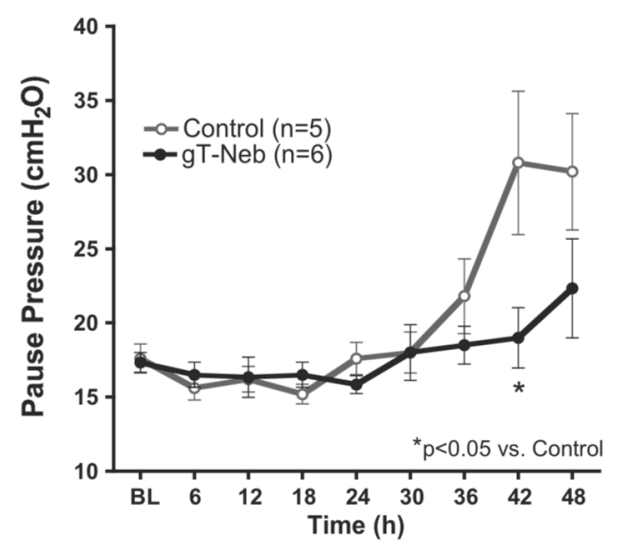

Figure 4.

Peak and Pause Pressures after Burn and Smoke Inhalation Injury with and without GammaTocopherol. After a 40\% TBSA full thickness burn and a smoke inhalation injury, sheep were killed after 96 hours. Results were compared to injured animals that were nebulized with vitamin E. Compliance was evaluated by measuring (A) peak pressure, and (B) pause pressure in the first 48 hours after injury. Peak and pause pressure both significantly decreased and improved with vitamin E treatment after 42 and 48 hours. Data are shown as means \pm SEM. $* P<0.05$ versus injured animals sacrificed after 96 hours. 


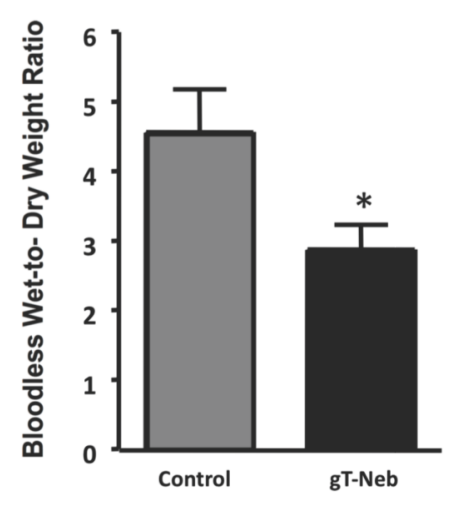

5B

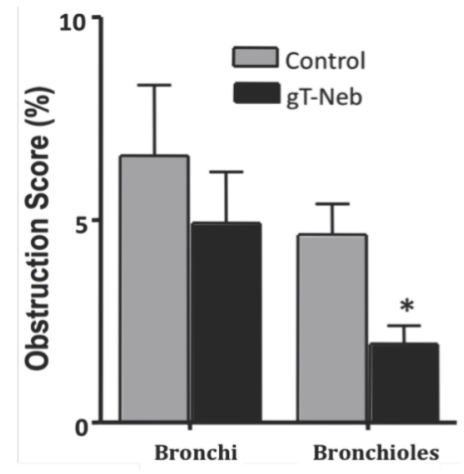

Figure 5.

Obstruction Scores of Bronchi and Bronchioles and Lung Wet-to-Dry Ratio after Burn and Smoke Inhalation Injury with and without Gamma-Tocopherol. After a 40\% TBSA full thickness burn and a smoke inhalation injury, sheep were killed after 96 hours. Results were compared to injured animals that were nebulized with vitamin E. Pulmonary pathophysiology was evaluated by measuring (A) bloodless wet-to-dry ratio, and (B) obstruction score. Both obstruction of the bronchioles and bronchi and wet-to-dry ratio significantly decreased and improved with vitamin E treatment after 42 and 48 hours. Data are shown as means \pm SEM. $* p<0.05$ versus injured animals sacrificed after 96 hours. 
6A
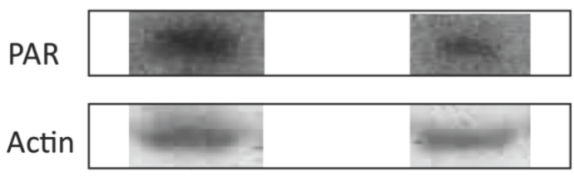

6B

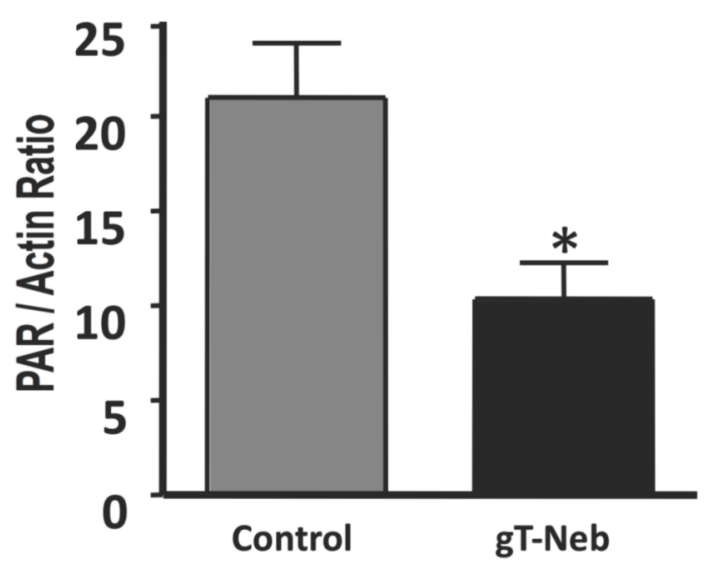

Figure 6.

Poly (ADP Ribose)-Polymerase (PAR) Activation Significantly Decreases with vitamin E Treatment after Burn and Smoke Inhalation Injury. After a 40\% TBSA full thickness burn and a smoke inhalation injury, sheep were killed after 96 hours. Representative Western blot analysis of the (A) poly(ADP-ribosylated) (PAR) proteins indicating the PARP activity in sheep lung. The poly(ADP-ribosylation) of the proteins was significantly decreased by 96 hours with vitamin $\mathrm{E}$ treatment after burn and smoke inhalation. Equality of protein loading was confirmed by the expression of $\beta$-actin. (B) Densitometric evaluation of PAR/actin ratios. Data are shown as means \pm SEM. $* \mathrm{p}<0.05$ vs. injured animals. 
Table 1

\begin{tabular}{|ccccc|}
\hline & & \multicolumn{3}{c|}{ Weaning Pattern } \\
\cline { 3 - 5 } Group & Animal Number & Start Weaning (h) & Off Ventilation (h) & Tube Removal (h) \\
\hline Control (n=5) & $\# 1$ & 70 & - & - \\
& $\# 2$ & - & - & - \\
& $\# 3$ & - & - & - \\
& $\# 4$ & 71 & - & - \\
& $\# 5$ & 90 & - & - \\
\hline gT-Neb (n=6) & Mean \pm SD & $77.0 \pm 11.3$ & - & 96 \\
& $\# 1$ & 69 & 78 & 96 \\
& $\# 2$ & 69 & 75 & 96 \\
& $\# 3$ & 48 & 94 & 54 \\
& $\# 4$ & 48 & 53 & 69 \\
& $\# 5$ & 48 & 68 & 72 \\
& $\# 6$ & 48 & 70 & $80.5 \pm 18.0$ \\
& Mean \pm SD & $55.0 \pm 10.8 *$ & $73.0 \pm 13.4$ & - \\
\hline
\end{tabular}

p $<0.05$ vs. Control 